\title{
Non-destructive Testing Robots (NDTBOTs) for In-Service Storage Tank Inspection
}

\author{
Richard Anvo ${ }^{1}$, Tariq P. Sattar ${ }^{1}$, Tat-Hean Gan ${ }^{2}$ and Ivan Pinson ${ }^{2}$ \\ 1. London South Bank Innovation Centre (LSBIC), TWI Ltd, Granta Park, Great Abington, Cambridge CB21 6AL, United Kingdom \\ 2. Integrity Management Group, TWI Ltd, Granta Park, Great Abington, Cambridge CB21 6AL, United Kingdom
}

\begin{abstract}
Petrochemical storage tanks are generally inspected when the tank is offline mostly to assess the extent of underside corrosion on the tank floor. Emptying, cleaning and opening a tank for inspection take many months and are very expensive. Inspection costs can be reduced significantly by inserting robots through manholes on the tank roof to perform non-destructive testing (NDT). The challenge is to develop robots that can operate safely in explosive and hazardous environments and measure the thickness of floor plates using ultrasound sensors. This paper reports on the development of a small and inexpensive prototype robot (NDTBOT) which is designed to be intrinsically safe for zone zero operation. The robot "hops" across the floor to make measurements, without any external moving parts. The paper describes the design, experimental testing of the NDTBOT and presents results of steel plate thickness measurements made under water.
\end{abstract}

Key words: Storage tank inspection, NDTBOT, in-service inspection.

\section{Introduction}

Storage tanks constructed of carbon steel degrade due to interaction with the stored materials, such as crude oil, oil products, petroleum chemical and raw petrochemical. Most tanks are constructed of plates welded together to form the structure. Over time corrosion, and in some circumstances, cracks can form that lead to leakage of the contents, resulting in economic costs and severe environmental pollution [1]. To avoid damage to the environment, inspection, evaluation, and repair activities are performed periodically according to American Petroleum Institute safety regulations (API) 653 [2] and Engineering Equipment and Materials Users Association (EEMUA) Publication 159 [3]. Most of the tank welds and surfaces, such as the walls and dome, which are subjected to these chemicals that are accessible from the outside. Current manual inspection methods mean the tank is out-of-service for

Corresponding author: Richard Anvo, PhD candidate, research field: non-destructive robot for storage tank inspection. several weeks, dependent on the size of the tank. Non-destructive testing (NDT) inspection requires transportation of the chemical product to alternative storage, and cleaning of the tanks before a human inspector can gain access to perform the inspection. These factors present several disadvantages such as implication cost, period to carry out inspection and, ultimately, loss of revenue due to downtime. High-risk exposure of workers to chemicals during the cleaning operation and inspection task is another limitation to human involvement in these tasks. Clearly, only external corrosion and welds can be inspected from outside [4], whereas corrosion of the tank floor can be inspected only from the inside.

\section{Overview of Storage Tank Robotics Inspections}

Several in-service storage tank floor inspection techniques have been implemented by tank owners and operators to assess corrosion and pitting. Aboveground storage tank (AST) bottom inspections are usually a combination of a number of NDT techniques; visual, ultra-sonic testing, magnetic 
particle testing and acoustic emission. Recently, Mohammad et al. [5] presented a paper on a wall-climbing mobile robot with a permanent magnetic adhesion mechanism that can be used for tank inspection. The robotic system consisted of a mobile platform, a three-wheeled locomotion unit and an adhesion mechanism that can move on a vertical wall. Andres [6] proposed a similar robot design with a teleoperated wall-climbing robot for oil tank inspection. He proposed a system consisting of wheel locomotion, which uses permanent magnets as the adhesion mechanism, and a cordless teleoperated mobile platform that can move on the vertical (ferromagnetic) wall. An umbilical free mobile NDT climbing robot for industrial applications was proposed by Sattar et al. [7]. This carries a single wheel probe operating between $1 \mathrm{MHz}$ and $10 \mathrm{MHz}$ to inspect defects, thickness and corrosion. This wall-climbing robot is capable of inspecting oil tanks, petrochemical tanks, bridges, and railways infrastructure. Kalra et al. [8] proposed a wall-climbing robot for non-destructive inspection of above ground tanks floors, which consists of an autonomous mobile platform that can move on the vertical walls of the tanks, carrying the probes for testing faults or internal cracks in the tank walls. Another robot for internal in-service inspection of petrochemical storage tank floors was presented by Sattar et al. [9], a wall-climbing robot to inspect the internal walls and floors of oil and petrochemical storage tanks. A surface switching mobile robot with buoyancy control used in RobTank was successfully tested in the water tank. In another development, Solex environmental systems, in conjunction with the Texas Natural Conservation Commission, developed and demonstrated the operation of Maverick [10], a remote-control robot system for inspecting in-service, aboveground petroleum and petrochemical storage tanks. Maverick performs floor inspections from inside the tank while submerged in refined products including gasoline, diesel and fuel oil, using a multi-channel ultrasonic sensor, on-board video system and a sonar-based tracking system. Similarly, a robot system for above-ground storage tank inspection Nep-tune [11] was proposed by the robotics institute and field robotics centre at Carnegie Mellon University. The complete system comprises a robot crawler vehicle carrying visual and ultrasonic sensors for AST inspection. The robot can be used in explosive petrochemical products for in-service inspection. Oil Tank Inspection System OTIS [12] is another robot designed to clean and inspect the steel floor of oil tanks while in operation. All the above developments of wall-climbing robots are capable of external inspection while internal in-service inspection remains challenging because none of these has the ability to inspect in-service storage tanks floors. The in-service inspection robots are designed for entry through manhole (300 mm) openings in the tank roof, power supply and NDT signal acquisition is via umbilical cables (about $100 \mathrm{~m}$ length) which is difficult to manage with tank internal heating coils. Long and heavy umbilical cables and moving parts such as wheels or crawlers are a significant impediment to inspection, and tank farm operator acceptance of these robots is challenging to achieve because of the very stringent safety requirements imposed by the operators.

The NDTBOT, small low power consumption and easy to deploy robot presented in this paper, does not require huge power cables or wheels, uses very low power electronics that are permitted in zone zero. The aim is to keep the robot cost low so that swarms of NDTBOTS can be used to perform the inspection and safely and economically abandoned where robot recovery is difficult or impossible depending on the tank size. About 15 to 20 NDTBOTS could be deployed simultaneously to inspect underside corrosion of a tank floor. Section 3 of this paper describes the NDTBOT design and prototype, whilst Section 4 describes control motion testing. In-service steel plate thickness measurements are presented in 
Section 5 followed by conclusions and future work in Section 6.

\section{NDTBOT Design and Prototype}

The first prototype of the NDTBOT has been developed to test its motion and inspection capability in a water tank. It comprises two sealed boxes, and buoyancy tank (B.T.) mounted on top of a box housing the electronics. The NDTBOT is made negatively buoyant by pumping in surrounding liquid and positively buoyant by pumping it out. The latter condition lifts the robot off the floor while simultaneously providing a force displacing it sideways using a pump. In this way, the robot is made to "hop" across the tank floor. A zero-degree ultrasound probe mounted on the bottom box is used to measure floor plate thickness. The first experimental prototype supplies DC power to the electronics box via a cable and retrieves NDT data via serial communications for processing with a commercial flaw detector outside the tank. The design aims to minimise the robot dimensions to present the smallest footprint possible on the floor and allow entry via the manhole of a petrochemical storage tank which have a minimum size of $300 \mathrm{~mm}$ diameter.

In order for the robot to perform inspections in an explosive and flammable environment such as storage tanks, the robot operation must avoid creating spark which can ignite an explosion in the tank due to heat and the presence of vapour mixture. Therefore, buoyancy tank (B.T.) will contain only flammable liquid and vapour, and/or air no heat sources and hence needs no protection. The bottom box housing all the electronics (battery, micro-pump, microcontroller, flaw detector and ultrasound probe), will be hermetically encapsulated in flameproof epoxy. The micro-pump is made of flame-proof material and will not get hot as it will be operated only for short periods to move the robot. Cable glands used on the first prototype are designed for underwater IP68. Therefore, with no moving parts, a sealed water tight box, and all electronics epoxy potted, the overall robot is likely to obtain ATEX approval for operation in flammable and explosive environments and be used in a storage tank for in-service inspection.

Fig. 1 shows the first prototype of the NDTBOT ready for testing in a laboratory water tank. Dimensions of the rectangular box shaped B.T. are $114 \times 89 \times 56 \mathrm{~mm}^{3}$ while the box housing the electronics is $140 \times 102 \times 77 \mathrm{~mm}^{3}$. The mass of the whole system is $1.67 \mathrm{~kg}$.

\section{Buoyancy Control System}

For underwater vehicle propulsion, thrusters are usually used. However, two disadvantages of this method are their high energy consumption and prohibited use of thrusters in a flammable and explosive environment. Energy storage is limited for submersible vehicles. Robots on data gathering missions in which they sit on the bottom of tanks and gather acoustic, video and chemical data over extended periods of time, need to conserve or harvest energy.

The NDTBOT uses a controllable buoyancy system to achieve motion with a single reversible micro-pump. It has the advantages of low cost, low energy consumption, simple operation, does not provoke perturbations in the environment of inspection and does not need to carry a heavy power cable.

\subsection{Micro-pump Description}

The micro-pump uses centrifugal force to pressurize and move liquid from the inlet to the outlet. A rotating

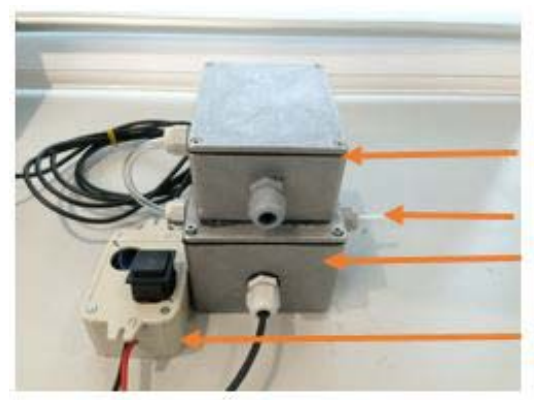

Buoyancy tank Inlet/Outlet Electronics house Control switch 
set of vanes (called an "impeller") is spun by the pump shaft. As liquid is forced through the impeller, rotational energy is transferred from the impeller to the fluid, which gains velocity and pressure through the centrifugal force applied and is flung from the impeller. The volute (a spiral-shaped case) funnels the now-pressurized liquid to the outlet. The pump is suitable for a wide range of viscosity, resists most chemicals and solvents and is self-priming. The pump is voltage controlled offering the advantage of controlling the flow rate of the pump. It has two tubing connectors made of stainless steel for easy and quick connection to the pipe. The pressure-flow rate characteristics of the micro-pump for different input voltage are shown in Fig. 2. These characteristics are important for design of the buoyancy control system as explained in Section 4.2.

\subsection{NDTBOT Buoyancy Tank and Electronic House}

The robot's variable B.T. and electronics house are rectangular aluminium boxes, with IP rating suitable for marine and industrial environments with operating temperature range of $-20^{\circ} \mathrm{C}$ to $280^{\circ} \mathrm{C}$. The buoyancy system starts on the surface of an oil tank at positive buoyancy just above neutral buoyancy. The tank will have both liquid and air trapped in the B.T. Adding more liquid to the B.T. will compress the air, increasing its pressure. The pump, therefore, must be capable of working against both pressures, when injecting liquid into the B.T. to sink the robot for inspection and also when expelling to move the robot to different location in tank. The maximum fluid depth of a petrochemical tank is $10 \mathrm{~m}$. The liquid pressure at a depth of $10 \mathrm{~m}$ will be 1 bar. Fig. 2 indicates that operating the pump at $6 \mathrm{~V}$ (to use mini-mum power) with a flow rate of $200 \mathrm{~mL} / \mathrm{min}$ will be sufficient to work against B.T. internal pressure in Table 2 and external pressures of 1 bar when expelling liquid to move to different location. If required, at $12 \mathrm{~V}$ the pump can operate at a pressure of 6 bar with a flow rate of $500 \mathrm{~mL} / \mathrm{min}$. The volume of fluid that flows into or out of the NDTBOT B.T. to make it descend/ascend determines the forces available for motion and can be calculated using Eq. (1).

$$
V_{d}(t)=\dot{V} \times t
$$

where, $\mathrm{V}_{\mathrm{d}}(\mathrm{t})$ is the volume of liquid added to the B.T., $t$ is the time taken to add the liquid and $\dot{V}$ is volume flow rate. The volume of fluid $\mathrm{V}_{\mathrm{d}}(\mathrm{t})$ added in a given time $t$ (flow rate) depends on the pump input voltage. Table 1 shows data for different voltages applied to the pump and the mass of liquid (water in this case) that is added at this time.

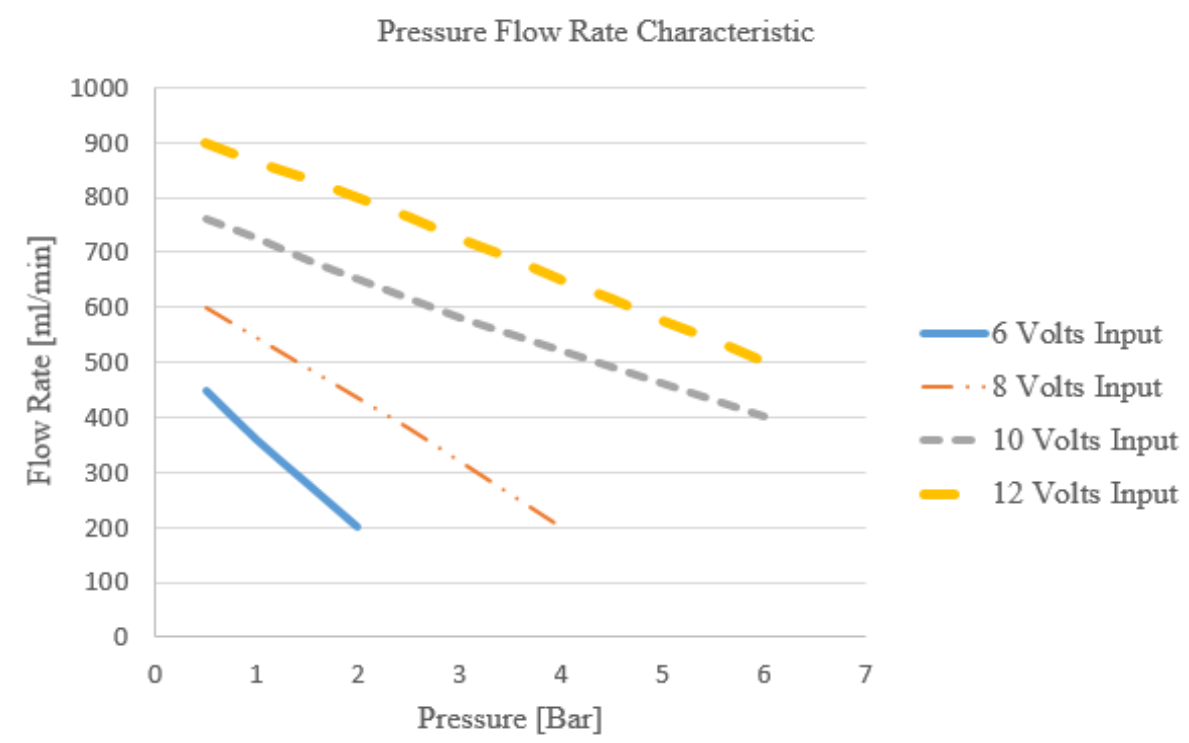

Fig. 2 NDTBOT thickness measurement of submerged. 
Table 1 Added liquid stating at neutral buoyancy.

\begin{tabular}{lll}
\hline Input voltage (V) & Volume added $(\mathrm{mL})$ & Liquid weight $(\mathrm{g})$ \\
\hline 6.0 & $7.5 \times t$ & $7.5 \times t$ \\
8.0 & $10 \times t$ & $10 \times t$ \\
10.0 & $12.7 \times t$ & $12.7 \times t$ \\
12.0 & $15 \times t$ & $15 \times t$ \\
\hline
\end{tabular}

Eq. (2) was used to calculate the pressure in the robot's B.T.:

$$
P_{1} V_{1}=P_{2} V_{2}(t)
$$

and

$$
P_{2}=\frac{V_{1}}{V_{1}+V_{d}(t)} \times P_{1}
$$

$\mathrm{P}_{1}$ and $\mathrm{V}_{1}$ represent the original pressure and volume of liquid in the B.T. at neutral buoyancy, and $\mathrm{P}_{2}$ represents pressure at a new volume $\mathrm{V}_{2} . \mathrm{V}_{\mathrm{d}}(\mathrm{t})$ is the volume of liquid being added to the B.T.

At time ( $t=0 \mathrm{~s}$ ) the pump is off, the NDTBOT is at the surface and pressure inside the B.T. is atmospheric pressure, i.e. $\mathrm{P}_{1}=1$ bar. Table 2 shows the corresponding increase in internal pressure when fluid is injected into the B.T. With an applied voltage of 6 $\mathrm{V}$; the pressure reaches approximately 1.9 bar in $35 \mathrm{~s}$ with increase in liquid volume of $263 \mathrm{~mL}$.

\section{NDT Experiments}

The ultrasonic testing (UT) methods used in the experiment are the pulse-echo technique: contact NDT and non-contact NDT with immersion probes. In the former case, the probe contacts the surface via an ultrasound couplant (water in this case). In the latter case, the ultrasound probe is kept at a constant stand-off distance from the surface with sound transmission through the liquid. A single transducer which acts as a transmitter, as well as the receiver, was used to measure the thickness of six different steel plates. The goal of this experiment was to measure the thickness of various steel plates using the NDTBOT submerged in a water tank and compare these measurements with prior measurements of original thickness with a Vernier caliper and results obtained with contact UT Ultrasonic Testing.

The experiment was conducted in three steps. First, the thickness of different plates was measured using a Vernier caliper at various places and averaged. Second, a conventional immersion ultrasound transducer (UT) was used to determine the thickness by manual scanning (contact NDT). Third, the UT probe was integrated with the NDTBOT with the probe at a constant stand-off distance from the plate surface (non-contact NDT) to as-certain the thickness of the same steel plates. Fig. 3 shows an experiment with three submerged steel plates. An Omnis-can flaw detector, power supply and control pendant were placed outside the tank and connected to the NDTBOT ultrasound probe and pump electronics. The probe used in the experiment was a conventional UT, single element, diameter $12.75 \mathrm{~mm}$, of frequency 2.25 MHz.

The A-Scan (Fig. 4) shows the graph from the Omnis-can flaw detector analysed with Tomoview software. The first edge-crossing method was used to read the signal with the gate $\mathrm{A}$ and gate $\mathrm{B}$. This means that when the first signal from the front wall reaches gate $\mathrm{A}$, a reading is taken, shown by an arrow, and the

\begin{tabular}{|c|c|c|c|c|c|c|c|c|c|}
\hline Time (s) & & 0 & 5 & 10 & 15 & 20 & 25 & 30 & 35 \\
\hline \multirow[t]{2}{*}{6 Volts } & Pressure (Bar) & 1 & 1.07 & 1.15 & 1.25 & 1.36 & 1.49 & 1.66 & 1.86 \\
\hline & Volume $\mathrm{V}_{\mathrm{d}}(\mathrm{t}) \mathrm{mL}$ & 0 & 37.5 & 75 & 112.5 & 150 & 187.5 & 225 & 262.5 \\
\hline \multirow[t]{2}{*}{8 Volts } & Pressure (Bar) & 1 & 1.1 & 1.21 & 1.36 & 1.54 & 1.79 & 2.12 & 2.60 \\
\hline & Volume $\mathrm{V}_{\mathrm{d}}(\mathrm{t}) \mathrm{mL}$ & 0 & 50 & 100 & 150 & 200 & 250 & 300 & 350 \\
\hline \multirow[t]{2}{*}{10 Volts } & Pressure (Bar) & 1 & 1.13 & 1.29 & 1.15 & 1.81 & 2.27 & 3.04 & 4.59 \\
\hline & Volume $\mathrm{V}_{\mathrm{d}}(\mathrm{t}) \mathrm{mL}$ & 0 & 63.5 & 127 & 190.5 & 254 & 317.5 & 381 & 444.5 \\
\hline \multirow[t]{2}{*}{12 Volts } & Pressure (Bar) & 1 & 1.15 & 1.36 & 1.66 & 2.12 & 2.94 & 4.81 & 13.16 \\
\hline & Volume $\mathrm{V}_{\mathrm{d}}(\mathrm{t}) \mathrm{mL}$ & 0 & 75 & 150 & 225 & 300 & 375 & 450 & 525 \\
\hline
\end{tabular}

Table 2 NDTBOT liquid tank characteristics. 


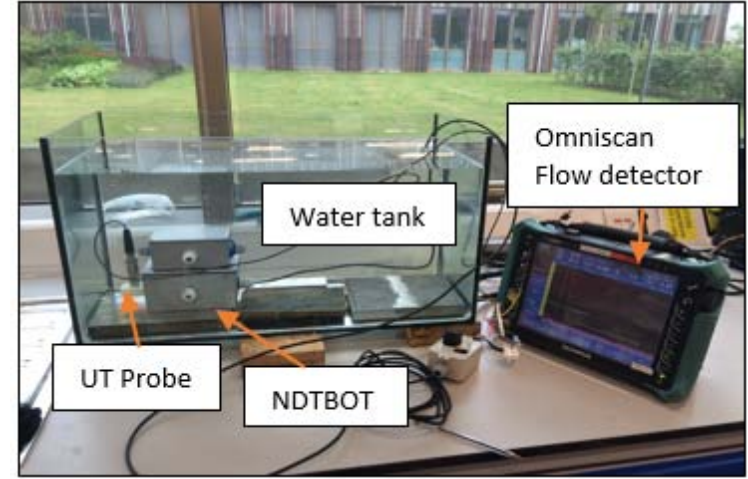

Fig. 3 NDTBOT thickness measurement of submerged steel plates.

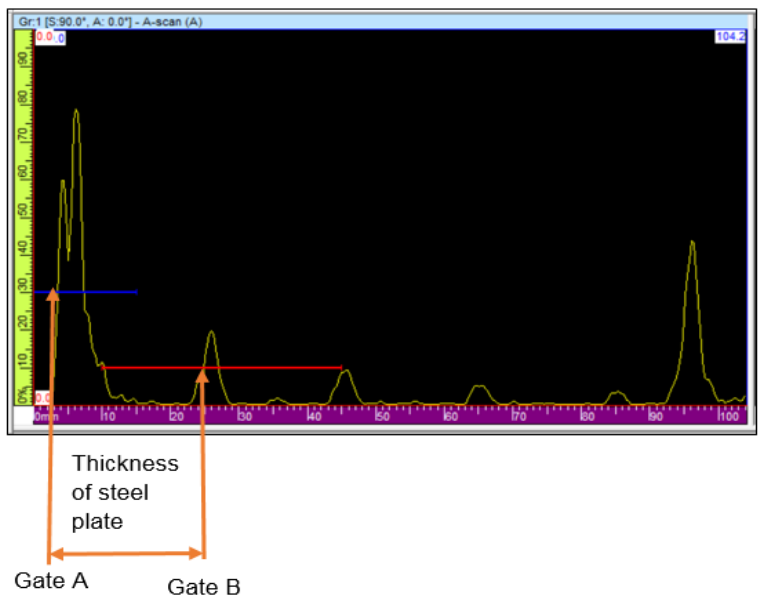

Fig. 4 A-scan UT NDTBOT immersion scan steel plate.

second reading is taken from the back wall at gate B, when the signal reaches the gate $\mathrm{B}$ arrow. The distance between the front wall and back wall echos represents the thickness of test block.

Fig. 5 shows the results of the average thickness measurement of the different steel plates during the experiment.

Table 3 shows the results of the margin of error as percentage was calculated with Eq. (3):

$\%$ Margin error $=\frac{\text { measured } \text { Thick }- \text { Real thick }}{\text { Real thick }} \times 100$

The UT contact margin of error is higher than the NDTBOT margin of error when compared to the real plate thickness. This is due to significant variation of pressure applied to the hand-held ultrasonic transducer during UT contact scanning. Therefore, NDTBOT measurement of plate thickness with non-contact NDT

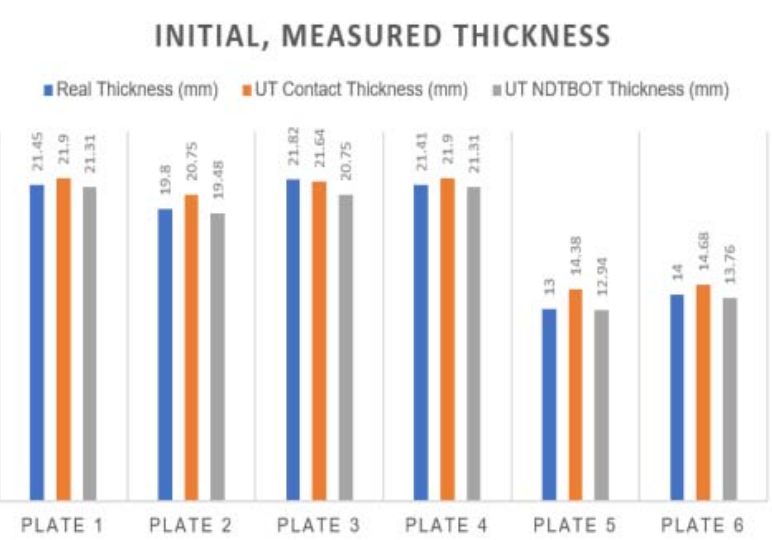

Fig. 5 Steel plates thickness measurement.

Table 3 \%Margin error measurement.

\begin{tabular}{lll}
\hline Plate & UT contact & UT NDTBOT \\
\hline 1 & $+2.10 \%$ & $-0.65 \%$ \\
2 & $+4.80 \%$ & $-1.61 \%$ \\
3 & $-0.82 \%$ & $+5.04 \%$ \\
4 & $-2.29 \%$ & $-0.47 \%$ \\
5 & $+10.62 \%$ & $-0.46 \%$ \\
6 & $+4.85 \%$ & $-1.71 \%$ \\
\hline
\end{tabular}

could in principle give more accurate results than an operator performing the measurements with contact NDT in an opened and vented tank.

\section{Conclusions and Future Work}

The first prototype of the NDTBOT has been developed in order to test its motion capability with a simple active buoyancy control method and to determine the quality of plate thickness measurements with non-contact ultrasound NDT. The NDTBOT thickness measurements with an immersion ultrasound probe obtained more accurate results than manual contact NDT. Therefore, the results increase confidence that using NDTBOTS to look for corrosion thinning on the floors of storage tank can give at least equivalent results than standard NDT performed by a human operator.

Future work will attempt to miniaturise the NDTBOT for low cost production, with on-board power, flaw detection, NDT data retrieval, communication, localisation and control capability for prolonged and autonomous inspection. The design 
will be engineered with a selection of suitable components, materials and procedures for safe operation in zone zero environments. It will be tested in petroleum product such as diesel or kerosene as well as oil sludge to analyse the capability of NDTBOT in real world storage tank inspection environment.

\section{References}

[1] Chang, J. I., and Lin, C. 2006. “A Study of Storage Tank Accidents." Journal of Loss Prevention in the Process Industries 19 (1): 51-9.

[2] American Petroleum Institute. 2014. API Standard 653: Welded Steel Tanks for Oil Storage. Washington: American Petroleum Institute.

[3] Engineering Equipment and Materials Users Association. 2014. EEMUA Publication 159: Above Ground Flat Bottom Storage Tanks: A Guide to Inspection, Maintenance and Repair. London: Engineering Equipment and Materials Users Association. FLEXChip Signal Processor (MC68175/D), Motorola, 1996.

[4] Kalra, L., Shen, W., and Gu, J. 2006. “A Wall Climbing Robotic System for Non Destructive Inspection of Above Ground Tanks.” In 2006 Canadian Conference on Electrical and Computer Engineering, 402-5.

[5] Moniri, M. M., Bamdad, M., and Sayyadan, M. Z. 2015.
"A Novel Design of Wall Climbing Robot for Inspection of Storage Steel Tanks.” In 2015 3rd RSI International Conference on Robotics and Mechatronics (ICROM), 557-62.

[6] San-Millan, A. 2015. "Design of a Teleoperated Wall Climbing Robot for Oil Tank Inspection.” In 2015 23rd Mediterranean Conference on Control and Automation (MED), 255-61.

[7] Sattar, T. P., Leon-Rodriguez, H. E., and Shang, J. Z. 2007. “Amphibious NDT Robots." In Climbing and Walking Robots: Towards New Applications, I-Tech Education and Publishing.

[8] Kalra, L. P., Gu, J., and Meng, M. 2006. “A Wall Climbing Robot for Oil Tank Inspection.” In 2006 IEEE International Conference on Robotics and Biomimetics, 1523-8.

[9] Sattar, T. P., and Leon-Rodriguez, H. 2013. "Surface Adaptation Robot for Defect Detection by Performing Continuously an Ultrasound Wheel Probe." In Nature-Inspired Mobile Robotics, 367-74.

[10] Maverick Demonstration "Submarine that Goes in Gasoline.” Solex Robotics, http://www.solexrobotics.com/Solex6.html.

[11] Schempf, H., Chemel, B., and Everett, N. 1995. "Neptune: Above-Ground Storage Tank Inspection Robot System." IEEE Robotics \& Automation Magazine 2 (2): 9-15.

[12] Techcorr.com. 2011. In-Service Tank Inspection, http://www.techcorr.com/in-service-tank-inspections.php. 